International Journal of Linguistics, Literature and Translation

ISSN: 2617-0299 (Online); ISSN: 2708-0099 (Print)

DOI: $10.32996 / \mathrm{ijllt}$

Journal Homepage: www.al-kindipublisher.com/index.php/ijltt

IJLLT

\title{
Gender-related Analysis in American Advertisements TV
}

\author{
Ghufran Sattar Jarad ${ }^{1} \square$ and Manal Ni'met Abdul Hadi ${ }^{2}$ \\ ${ }^{1}$ M.A. Student, Department of English Language and Literature, College of Arts, Mustansiriyah University, Iraq \\ ${ }^{2}$ Assistant Professor, Department of English Language and Literature, College of Arts, Mustansiriyah University, Iraq \\ $\square$ Corresponding Author: Ghufran Sattar Jarad, E-mail: Ghufran.satar91@gmail.com
}

\section{ARTICLE INFORMATION}

Received: 15 September 2021

Accepted: 15 October 2021

Published: 30 October 2021

DOI: 10.32996/ijltt.2021.4.10.13

\section{KEYWORDS}

Advertisements, gender, ideational, interpersonal, textual meta-functions

\section{ABSTRACT}

Advertising is "the non-personal communication of information usually paid for and persuasive in nature about product, service or ideas by identified sponsors through the various media" (Buren,1992:7). The ad aims to market products and services, this is according to business and this is an effective marketing tool. Advertising also offers information so that customers are aware of what is available, who makes it, and where they can get it (Durant \& Lambron, 2009: 93). Advertisers need to consider gender differences to the best capacity possible to use appropriate advertisement design features. The most significant aspect of gender issues for advertisers can be how males and females react differently to the advertisement. So, "the focus is on how gender in language and society is negotiated and how linguistic forms represent and shape social and cultural conditions in which men and females live". (Behnam and Zamanian, 2014:4) American advertisements often contain different meta-functions that are worthy of analysis. The present study intends to analyze American advertisements according to the three meta-functions such as ideational, interpersonal, and textual. This study examined 5 American advertisements (each one of them has a different theme) from a verbal and non-verbal perspective, based on the three meta-functions models developed by Halliday (1994). The results of the study revealed that American advertisements are biased to females rather than males to introduce the products because they considered females as powerful signs who use their high attractiveness to promote the products or brands. Concerning the grammatical aspects, the results showed that material process, mental process, declarative mood, and first-person pronouns are the highest used to achieve the goals of this study.

\section{Introduction}

Richard and Curran define advertising as "is a paid, mediated form of communication from an identifiable source, designed to persuade the receiver to take some action, now or in the future. According to the authors, "mediated communication" is the "information that is transmitted to the public through printing, electronics, or other methods than individual interaction." The current definition of ad, however, presents a variety of problems (Richard and Curran, 2002:74).

The paper focuses on understanding how advertisements on American TV are used to persuade about products, services, or ideas. Hence, this paper aims to analyze American TV advertisements and investigate how advertisers use verbal and non-verbal aspects to make viewers buy into their products, and state the role of gender-related in American TV advertisements. The paper proceeds as follows. Section 2 introduces the theoretical background. Section 3 introduces data and methodology. Finally, section 4 presents the main conclusions.

\section{Theoretical Background}

In Halliday's systematic functional linguistics (SFL), "language as a social phenomenon is functional, i.e. it is concerned with the mechanism of the test structure, function and meaning of language". The SFL model's linguistic element is divided into three metafunctions: ideational, interpersonal, and textual (Banks, 2002:2-3).

\subsection{The Ideational Meta-Function}

Copyright: (c) 2021 the Author(s). This article is an open access article distributed under the terms and conditions of the Creative Commons Attribution (CC-BY) 4.0 license (https://creativecommons.org/licenses/by/4.0/). Published by Al-Kindi Centre for Research and Development, London, United Kingdom. 
According to Halliday (1994), register variations are systemically related to the three metafunctions of language. The ideational meta-function is the component that deals with how the text illustrates external reality. Transitivity is an important part of the ideational metafunction. Transitivity in SFL refers to more than the conventional differences between transitive and intransitive verbs; it refers to the type of process that a clause entails, the participants affected, and, if applicable, the accompanying circumstances. Thus, transitivity refers to the existing relationships between all the processes, participants, and circumstances embedded in the clause. As several types of procedures are employed in the study, the focus is on characterizing the various types of procedures and their connected configurations of specific roles (Banks, 2002:2-3).

\subsubsection{Material processes}

Eggins (2004:215) states that materials processes include those that concern "doing" or concrete, tangible actions. They convey the concept that something (whether a person or an object) does something, going about doing it, with the possibility that something is done to another object (person or inanimate object). Participants make an action happen. Nominal organizations are a group of members.

Example (1):

The lion caught the tourist

Actor Process Goal

\subsubsection{Mental Processes}

Halliday (1994:118) categorizes mental process verbs as comprehension (verbs of thoughts, recognizing, and understanding), affection (verbs of admiring, fearing), and awareness (verbs of awareness) (verbs of seeing, hearing). As long as an aware human being is involved, there will always be a sensor, a feeler, or a perceiver. They refer to this participant as a Senser.

Example (2):

$\begin{array}{lll}\text { I believe you } & \text { you } \\ \text { Sensor Process Phenomenon }\end{array}$

\subsubsection{Behavioral Processes}

Behavioral processes are the third procedure. These procedures are semantically described by Halliday as a "halfway house" among mental and material processes. Behaviors are physiological and psychological processes that occur in humans. As a result, behavioral reveal a way of doing things that do not normally broaden to another person. (Eggins, 2004:215)

Example (3):

$\begin{array}{lll}\text { Sarah } & \text { is } & \text { wise } \\ \text { Carrier } & \text { Process Attribute }\end{array}$

\subsubsection{Verbal Processes}

A verbal process, according to Halliday (1994), comprises three main participants: Sayer, Receiver, and Verbiage. The Sayer, or the person in charge of the verbal process, does not seem to be an aware participant (though it usually is), but can be anything that can send out a signal. The Receiver is the person to which the verbal process is aimed directly: the recipient of a verbal message, which may or may not include a preposition based on the clause's situation. Verbiage is a nominalized declaration of the verbal process: it is a noun that expresses some type of human personality. (Ibid)

Example (4):

John answered the question
Sayer Process Verbiage

\subsubsection{Relational Processes}

Relational processes encompass a wide range of ways of expressing being in English agreements. Eggins (2004:214) defines the fundamental structural distinction between "Attributive and Identifying" procedures. "Possessives and circumstantials" are two additional types of relational processes. Possessives converse between clausal respondents the significance of ownership and possession. 
Example (5):

$$
\begin{array}{cl}
l & \text { weep for you } \\
\text { Behaver } & \text { process }=\text { behavioral }
\end{array}
$$

\subsubsection{Existential Processes}

Existentials are visible because their structure includes the word "there." According to Eggins (2004), "there has no representational meaning when used in existential processes: it does not refer to a location" (p. 214). Existential processes frequently use the verb 'be' or vocabulary such as 'exist, arise, or occur.' The Existent has been the only obligatory member in an existential process who obtains a useable label. This member, which typically follows the 'there is/are' series, could be that kind of occurrence and is frequently an incident (nominalized action).

Example (6):

$$
\begin{array}{ll}
\text { There is a man at the door } \\
\text { Process=existential Existent } & \text { Circumstance=place }
\end{array}
$$

\subsection{The Interpersonal Meta-Function}

The interpersonal meta-function is concerned with the correlations between the communicator and his or her addressee(s), as well as the communicator and his or her message. The mood is an important aspect of an interpersonal meta-function. "A Mood element and a Residue" are used to analyze mood. "The Finite and the Subject" combine to form the Mood element. The Finite, which isn't identified or separated in any other principle, is the component that, in conjunction with the Subject, focuses on describing the mood of a clause. The Finite is embedded during the first (leftmost) auxiliary of the verb phrase in English. As a result, the sequence Subject Finite creates a declarative mood, whereas the sequence Finite Subject creates an interrogative mood.

\subsection{The Textual Meta-Function}

The textual meta-function is the portion of the possible meaning that transforms a set of clauses into a text. It, therefore, involves "thematic structure, information structure, and cohesion." Thematic structure, or an analysis of the sentence in terms of Theme and Rheme, is one of the major textual meta-functions. (Banks, 2002:2-3)

\section{Data and Methodology}

This paper analyzes 5 advertisements on American TV. These ads are selected from different American channels and to be analyzed on the principle of ideational, interpersonal, and textual meta-function that follows Halliday's (1985) framework. Methodologically, this paper is designed within the configuration of qualitative research. A meta-function will be used for text analysis. However, this paper sheds light on the concern of phrases in advertisements, as a literary version, to realize ideational, interpersonal, and textual meta-functions, about how they represent reality in culture. In this case, this paper depends on the hallidyian Systematic Functional Grammar (SFG) model of text analysis as a frame of reference or as an analytical process in this paper to analyze the meta-functions of clauses in ads as a model of analysis.

\section{Data Analysis}

The text of advertisements is collected to be analyzed that based on Halliday's (1985) framework. Then, the ads are used in this paper are 5 from American TV, and these ads based on 5 themes which are selected randomly from different channels.

\subsection{Sample Advertisement about Perfume}

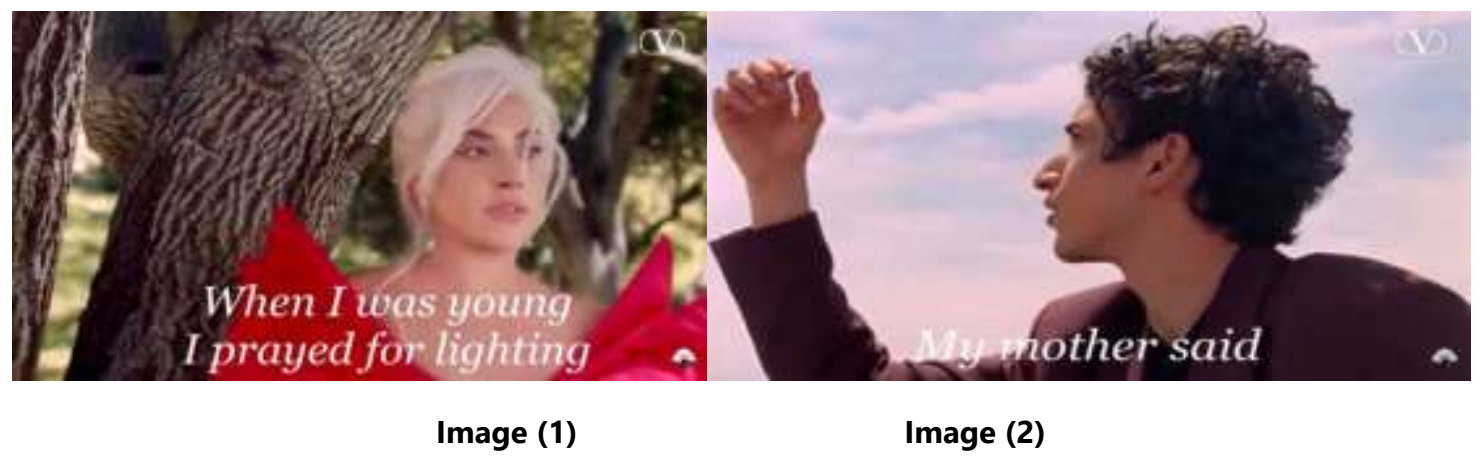




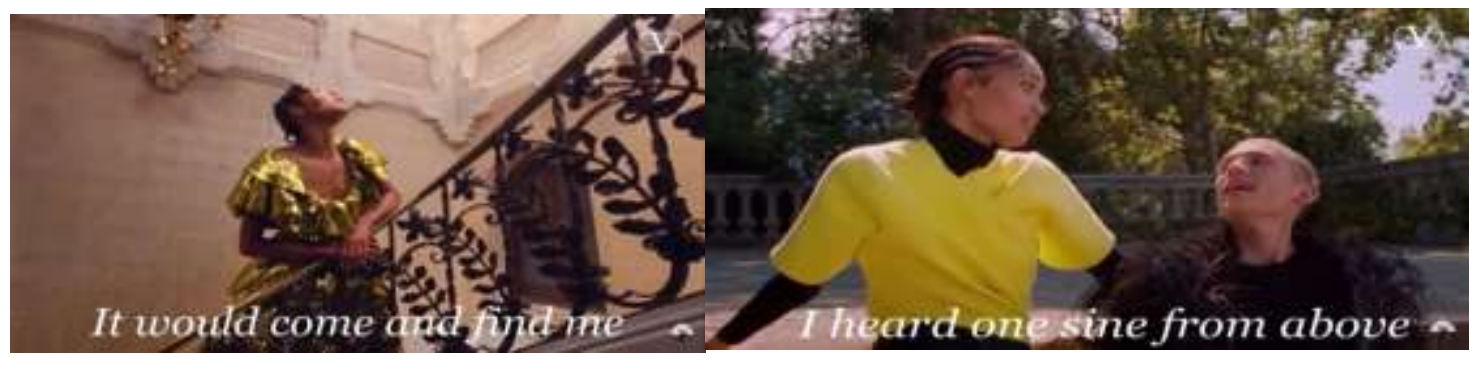

Image (3)

Image (4)

The favored linguistic code is English, in the images above. With respect to Kress and Leeuwen's (2006) meta-functions, the following analysis is reached at:

\subsubsection{Ideational meta-function:}

As mentioned earlier, this function is realized in terms of transitivity variables, as shown below:

a. Image (1): when I was young I prayed for lighting

The transitivity analysis appears in this clause, and it is a verbal group encoding a process, was young, which takes place in a physical environment, and then is a relational process. It is represented by a relationship of equivalence between two entities that is I is young, while I prayed for lighting, which means that $I$ is an attributive of young, and I prayed is an attributive of lighting.

b. Image (2): My mother said

The clause is regarding a verbal process. As for image (2), the phrase my mother is the sayer, while the verb said is the process of the sentence.

c. Image (3): It would come and find me

The mental process uses in the above sentence. This process has three components, as in, It sensor, would come and find process, and me phenomenon.

d. Image (4): I heard one sine from above

This sentence has a mental process. So, $I$ is the sensor, heard is the process, and one sine from above is the phenomenon. From the above analysis, one can understand that all the four images shared with the perfume are extracted from nature.

4.1.2 The interpersonal meta-function:

This function is realized according to Halliday SFG (1985) in terms of mode of discourse which is associated with thematic information structures as shown below:

\begin{tabular}{|c|c|c|}
\hline \multirow{2}{*}{$\begin{array}{l}\text { Image } \\
\text { No. }\end{array}$} & \multicolumn{2}{|l|}{ Theme } \\
\hline & Interpersonal Textual & \\
\hline 1 & & $\begin{array}{l}\text { when } \\
\text { for lighting }\end{array}$ \\
\hline 2 & & \\
\hline 3 & Would & and \\
\hline 4 & One & from above \\
\hline
\end{tabular}

Table (1): Interpersonal Analysis of Perfume (Valentino) Perfume in American Advertisement

The themes submitted in the table (1), it's manifest that the wide majority shows interpersonal and textual themes. 


\subsubsection{Textual meta-function:}

As mentioned earlier, this function is associated with tenor patterns of discourse which is realized in terms of mood and modality structures. Only mood components will be foxed at as is shown below:

\begin{tabular}{|c|c|c|c|c|c|c|}
\hline \multirow{2}{*}{$\begin{array}{l}\text { Image } \\
\text { No. }\end{array}$} & \multicolumn{2}{|l|}{ Mood } & \multicolumn{3}{|l|}{ Residue } & \multirow[t]{2}{*}{ Types of Mood } \\
\hline & Subject & Finite & Predicator & Complement & Adjunct & \\
\hline 1 & $\begin{array}{l}1 \\
1\end{array}$ & $\begin{array}{l}\text { past } \\
\text { past }\end{array}$ & $\begin{array}{l}\text { was } \\
\text { prayed }\end{array}$ & young & for lighting & $\begin{array}{l}\text { Declarative } \\
\text { Declarative }\end{array}$ \\
\hline 3 & It & past & come & and find me & & Declarative \\
\hline 4 & I & past & heard & one & sine from above & Declarative \\
\hline
\end{tabular}

Table (2): Textual Analysis of Perfume (Valentino) in American Advertisement

By sharing the mood structure, appearing in the table (2) above clause by clause, it appears clear that the ads proceed as sequences of declarative mood. The mood is managed for the arranging of the texts of an ad. So, it assumes one who gives information through an ad and one who receives it. The advertiser uses the pronouns $I, m y$, and it to make a relation between him and his readers. In addition, according to declarative mood, the writer uses all ads (declarative mood) as shown in table (2).

On the visual level, The signal used in the images (1),(2), (3), and (4) is the voice of the female and male to show the viewers that the voice is the power of the human, and the signal is also provided by nature. In an index in the images (1),(2),(3), and (4), the perfume of Valentino draws a parallel between the sound of her/his voice and the scent of her/his fragrance. As a voice, a fragrance is personal, intimate, and leaves a trace. The symbols used in this advertising are "tress and sky" in the images (1),(2), and (4) to show the conventional connection between these symbols and its perfume of Valentino. However, the name that uses in image (1) is the well-known person "Lady Gaga", to celebrate every woman's voice in one advertisement. The phrase "I heard one sine from above" in image (4) shares with the words of the song of Lady Gaga that use to draw the attention of viewers. Denotation played an important role rather than connotation. With the use of nature as a sign of the perfume and the use of a red dress to share the color of the perfume bottle, all the images that appear in the ad denote that the perfume is taken from nature. Nature is considered to place semiotics because these places share that the perfume extract from nature. The role of the female in this advertisement by using a famous person like "Lady Gaga" to compare between woman's voice and her perfume, also to show that her voice is her strength. The use of both females and males in this advertisement order to shows there is no difference between cultures and ethnicities.

\subsection{Sample Advertisement about Phone}

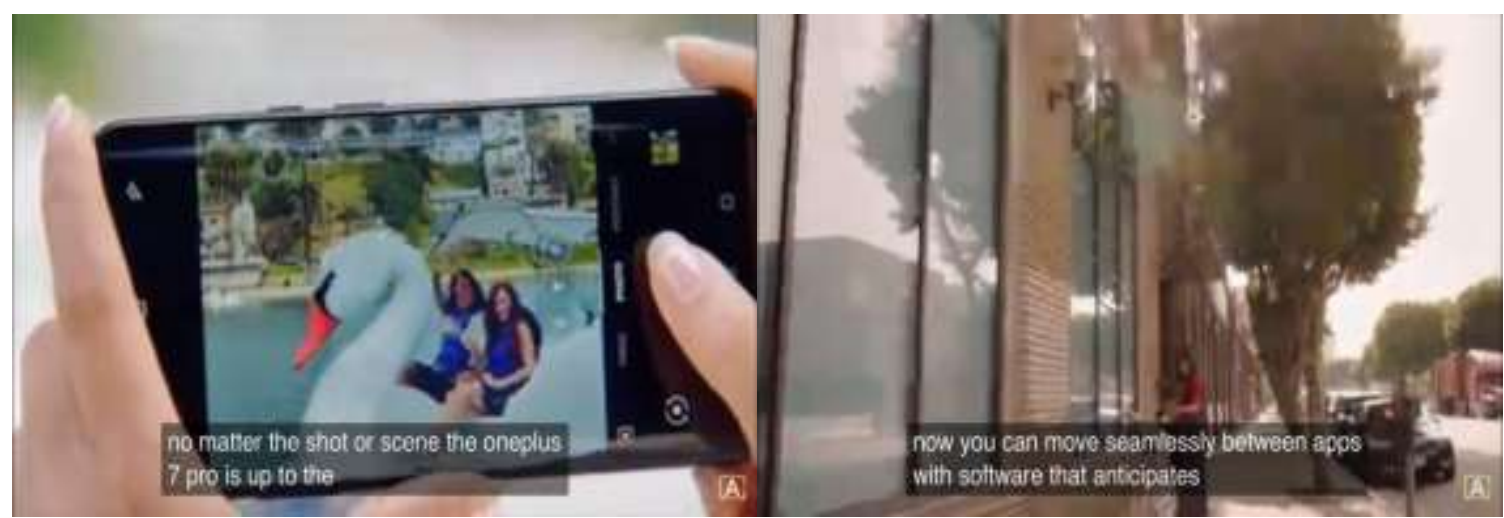

Image (1)

Image (2)

On the textual level, the favored linguistic code is English. According to Halliday's (1985a) meta-functions, the following analysis is defined as follow: 


\subsubsection{Ideational meta-function}

The American ads collected in terms of three main meta-function, such as ideational, interpersonal, and textual meta-functions, as shown below:

a. Image (1): now you can move seamlessly between apps with software that anticipates

Image (1) presents the unknown character, which doesn't like Lady Gaga in the first American Advertisement. According to Halliday's (1994) meta-functions, the text of image (1) consists of a material process in which now you is the actor, can move is the process, seamlessly is the goal, and between with software that anticipates is the phenomenon.

b. Image (2): no matter the shot or scene the one plus 7 pro is up to the task

The text of image (3) contains a material process, no matter the shot or scene is the circumstance, the one plus 7 pro is the goal, and is up to the task is a material process.

\subsubsection{Interpersonal meta-function}

The sentence of image (1) contains the personal pronoun you in addition to the modal verb can. The analysis of this function is expressed in the following table:

\begin{tabular}{|l|l|l|}
\hline \multirow{2}{*}{$\begin{array}{l}\text { Image } \\
\text { No. }\end{array}$} & \multicolumn{2}{|l|}{ Theme } \\
\cline { 2 - 3 } & Interpersonal & Textual \\
\hline 1 & now & that \\
& can & with \\
\hline 2 & seamlessly & or \\
& & is \\
& & no \\
\hline
\end{tabular}

Table (3): Interpersonal Analysis of phones (Samsung) in American Advertisement

The previous table shows that image (1) starts with the interpersonal theme now which regards as an interactive mood. While image (2) starts with the textual theme no.

\subsubsection{Textual meta-function}

The analysis of mood patterns shown in the parts is explained in the table below:

\begin{tabular}{|c|c|c|c|c|c|c|}
\hline \multirow{2}{*}{$\begin{array}{l}\text { Image } \\
\text { No. }\end{array}$} & \multicolumn{2}{|l|}{ Mood } & \multicolumn{3}{|l|}{ Residue } & \multirow{2}{*}{ Types of Mooc } \\
\hline & Subject & Finite & Predicator & Complement & Adjunct & \\
\hline 1 & You & present & can & move & seamlessly & Declarative \\
\hline 2 & $\begin{array}{l}\text { Oneplus } 7 \\
\text { pro }\end{array}$ & present & is & & up to & Declarative \\
\hline
\end{tabular}

Table (4): Textual Analysis of Phones (Samsung) in American Advertisement

As illustrated in the analysis of American advertisements in the table (4), that all reference the declarative mood. Both images share the present tense. It's important to note that females played an important role in this advertisement. 
On the visual level, the above images are part of the advertisement. The symbols (sunlight, the girl rides a bike rather than the car, and so on) used in these two images share that the phone bears the environmental changes, whether under the sun or under the water. The researcher will take apart of denotation and connotation of these images. First, for the denotative meaning, there's a girl riding a bike and using her phone in the street. Second, the connotative meaning of this advertisement is that the type uses sunlight with the phone to show that the phone is not affected by the hot sun. According to Scollon and Scollon's model, the two places use in the two images, the street in the image (1), and the water in the image (2) as mentioned above which show that the phone doesn't affect by the environment. It's important to note that females played an important role in this advertisement. The sign of female use rather than male to show the beauty of her to promote the product. A lot of companies use females rather than males as a symbol of beauty and encourage the viewers to buy the product.

\subsection{Sample Advertisement about Competitions (Top Chef)}

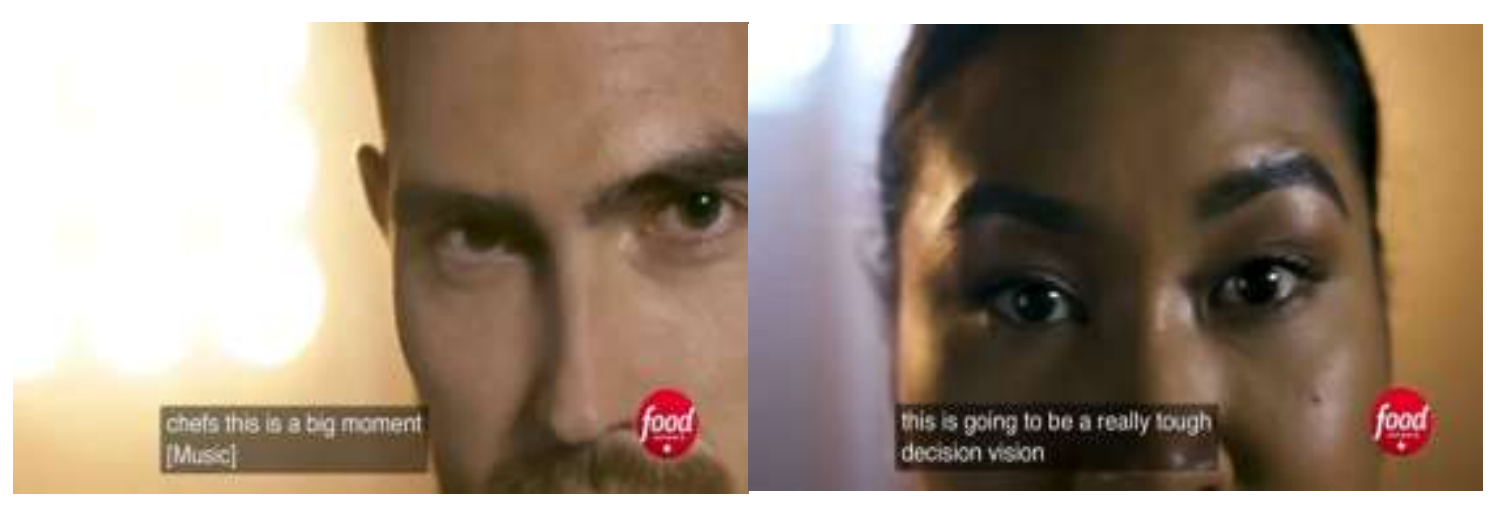

Image (1)

Image (2)

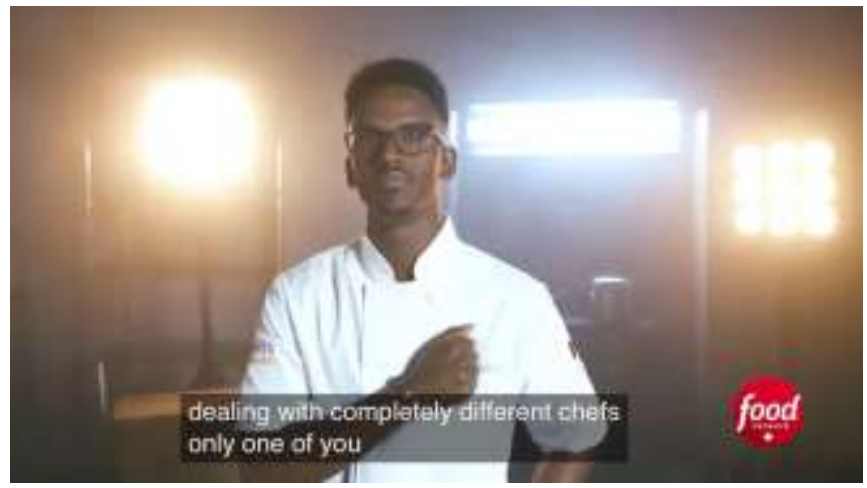

Image (3)

English is the preferred linguistic code. These three images $(1,2,3)$ introduce the program of Top Chef in the American channel of food. Halliday's three meta-function will be used in the analysis:

\subsection{Ideational meta-function}

The term ideational meta-function used by Halliday denotes the use of dialect to communicate content, figures of experience, and convey information. The analysis refers below:

a. Image (1): Chefs this is a big moment

The representative text is obvious in image (1), which uses the verbal process in the analysis of an advertisement. Chefs is the sayer, this is is the process, and a big moment is a verbiage.

b. Image (2): This is going to be a really tough decision vision

In image (2), the use of the material process to express "the doer of the action" . is going is the actor, to be is the process, and $a$ really tough decision vision is the goal.

c. Image (3): Dealing with completely different chefs only one of you

The text in image (3) uses the existential processes. Dealing with is the process of existential, completely different chefs is the existent, and only one of you is the circumstance. 


\subsubsection{Interpersonal meta-function}

Interpersonal is another type of meta-function. However, these three images are analyzed in the following table:

\begin{tabular}{|c|c|c|}
\hline \multirow{2}{*}{$\begin{array}{l}\text { Image } \\
\text { No. }\end{array}$} & \multicolumn{2}{|l|}{ Theme } \\
\hline & interpersonal & textual \\
\hline 1 & is & this \\
\hline 2 & $\begin{array}{l}\text { is } \\
\text { really }\end{array}$ & this \\
\hline 3 & completely & $\begin{array}{l}\text { with } \\
\text { only } \\
\text { one }\end{array}$ \\
\hline
\end{tabular}

Table (5): Interpersonal Analysis of Competition (Top Chef) Advertisement

The interpersonal themes in these three images reach the declarative mood. While the textual themes that used by the narrator to successfully make a relation between patterns.

\subsubsection{Textual meta-function}

Analysis of American's Top Chef advertisement is illustrated below:

\begin{tabular}{|c|c|c|c|c|c|c|}
\hline \multirow{2}{*}{$\begin{array}{l}\text { Image } \\
\text { No. }\end{array}$} & \multicolumn{2}{|l|}{ Mood } & \multicolumn{3}{|l|}{ Residue } & \multirow{2}{*}{ Types of Mood } \\
\hline & Subject & Finite & Predicator & Complement & Adjunct & \\
\hline 1 & chefs & present & is & & $\begin{array}{l}\text { a big } \\
\text { moment }\end{array}$ & Declarative \\
\hline 2 & & present & is & going & $\begin{array}{l}\text { a really } \\
\text { tough } \\
\text { decision } \\
\text { vision }\end{array}$ & Declarative \\
\hline 3 & $\begin{array}{l}\text { different } \\
\text { chefs }\end{array}$ & present & dealing & with completely & $\begin{array}{l}\text { only one of } \\
\text { you }\end{array}$ & Declarative \\
\hline
\end{tabular}

Table (6): Textual Analysis of competition (Top Chef) Advertisement

In this system, the investigation of mood asserts the situation of declarative mood as the controlling one. Within this analysis, it's clear that the narrator uses certain sentences to refer to the challenge between chefs such as "Dealing with completely different chefs", and " only one of you".

The visual structure of the signs of eyes in the images $(1,2)$ represents the power and challenge between them. Also, the sign of hand in image (3) implies the participant will be a win and he will take the title of the American world. The denotation and connotation of these three images $(1,2,3)$, in this study, will describe denotation and connotation in each image. The term denotation, according to Mahine (2007), "is literal meaning or data information", whereas connotation "is hidden meaning of a sign, or it's also called a message which is found in a sign." The denotative in these three images $(1,2,3)$, there're three participants in American's program of Top Chefs. In the connotative, these three participants challenge each other to win in the Top Chefs. In addition, the place semiotics shown in these three images $(1,2,3)$ share that all images correlate with each other by the background, colors, and lights that appear behind each of them. The different gender and cultures show in the advertisement, which deals with different nationalities. 


\subsection{Sample Advertisement about Shampoo (Dove)}

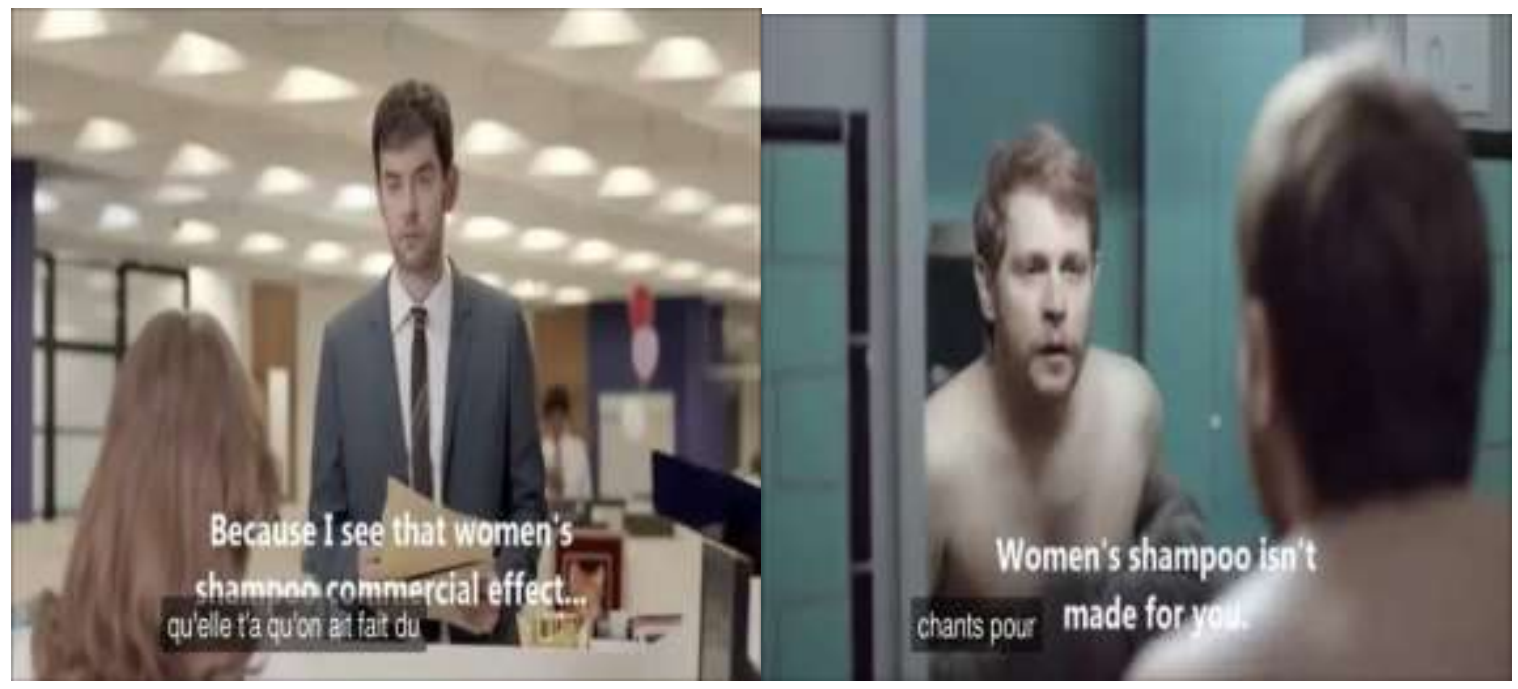

Image (1)

Image (2)

The favored linguistic code is English. The two images $(1,2)$ present the American's Dove shampoo product. According to Kress and Leeuwen's meta-functions, The following analysis of meta-functions is shown below:

\subsubsection{Ideational meta-function}

The ideational meta-function helps to determine the seven processes of advertisement, the processes present in the following analysis:

a. Image (1): because I see that women's shampoo commercial effect...

First, the image presents an unknown character. The text of image (1) involves a material process in which that women's is the actor, shampoo is the process, and commercial is the phenomenon.

b. Image (2): women's shampoo isn't made for you

The text in image (2) consists of a mental process in which women's shampoo is the sensor, isn't made is the process, and for you is the phenomenon.

\subsubsection{Interpersonal meta-function}

The text of image (1) involves a personal pronoun I, whereas image (2) also uses the personal pronoun you, the text of these two images $(1,2)$ forms by the interpersonal and textual themes, the thematic structure is as follows:

\begin{tabular}{|l|l|l|}
\hline \multirow{2}{*}{\begin{tabular}{l} 
Image \\
\cline { 2 - 3 }
\end{tabular}} & \multicolumn{2}{|l|}{ Theme } \\
\cline { 2 - 3 } & interpersonal & textual \\
\hline 1 & & that \\
\hline 2 & isn't & for \\
\hline
\end{tabular}

Table (7): Interpersonal Analysis of Shampoo (Dove) in American advertisement

The advertiser informs viewers by using the word that, it shares to women which use this shampoo to get along and healthy hair. 


\subsubsection{Textual meta-function}

The analysis of mood structures in these two images $(1,2)$ will be shown in the table below:

\begin{tabular}{|c|c|c|c|c|c|c|}
\hline \multirow{2}{*}{$\begin{array}{l}\text { Image } \\
\text { No. }\end{array}$} & \multicolumn{2}{|l|}{ Mood } & \multicolumn{3}{|l|}{ Residue } & \multirow{2}{*}{ Types of Mood } \\
\hline & Subject & Finite & Predicator & Complement & Adjunct & \\
\hline 1 & $\begin{array}{l}\text { I } \\
\text { Women's } \\
\text { shampoo }\end{array}$ & present & & see & $\begin{array}{l}\text { commercial } \\
\text { affect }\end{array}$ & Declarative \\
\hline 2 & $\begin{array}{l}\text { Women } \\
\text { shampoo }\end{array}$ & present & is & made & for you & Declarative \\
\hline
\end{tabular}

Table (8): Textual Analysis of Shampoo (Dove) in American Advertisement

It's seen in the table above the same subject women's shampoo that was used in two images $(1,2)$, to emphasize the production of shampoo.

On the visual analysis, the symbol of long hair used in the first image encourages the women's viewers to buy this product and to show the power of this product. Denotative meaning in the image (1) there's a man who has long and beautiful hair, and his friend is shocked by his beautiful hair. While the connotative meaning, in the image (1) if a woman wants her hair to be long, strong, and beautiful, she must use this shampoo, and if men don't want long hair he must avoid the women's shampoo. The interaction order which uses in the image (1) by the man when sees his friend which has long hair, and another interaction order appears in the image (2) in the bathroom when he sees himself in the mirror and is afraid about his hair. The gender used in this advertisement is men rather than women. For this reason, the audience's attention about the man's hair, so there's no need for women in this advertisement because a man has two roles when he has long hair like a woman, and when he has short hair

\subsection{Sample Advertisement about Automobile (The Heist)}

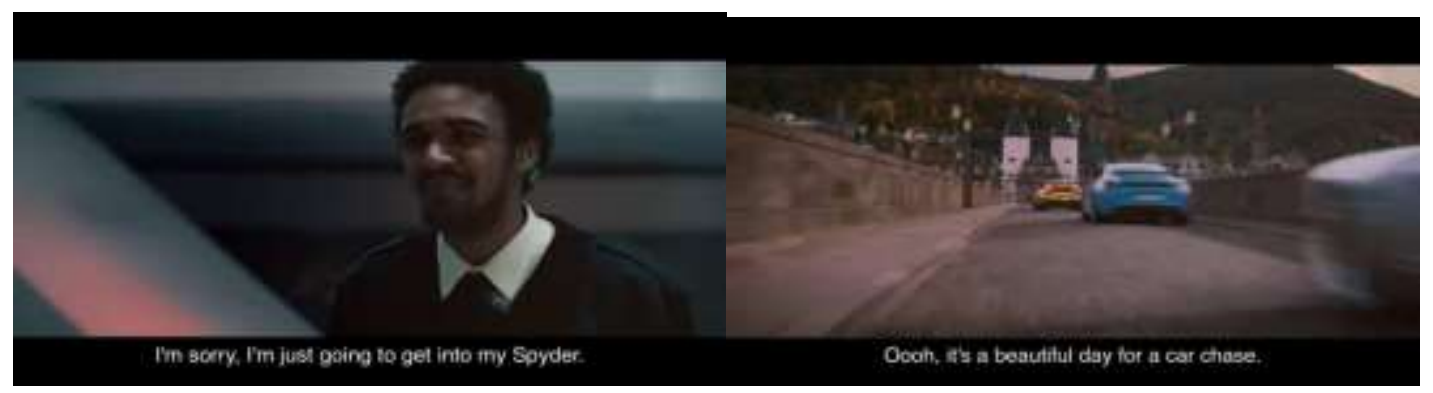

Image (1)

Image (2)

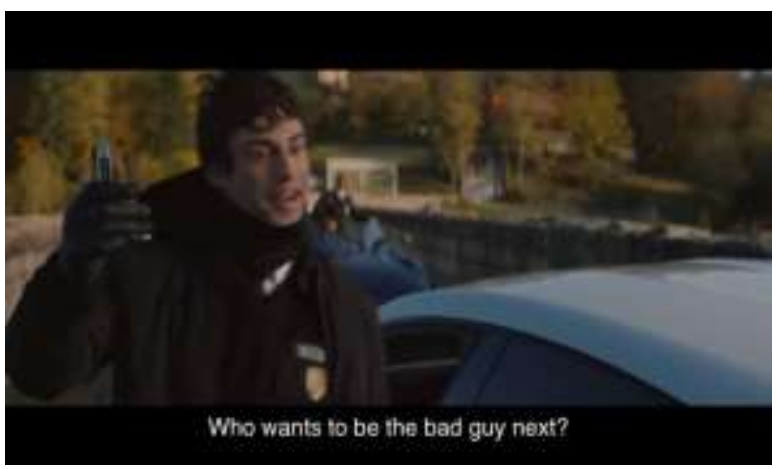

Image (3) 
The favored linguistic code is English. These three images $(1,2,3)$ introduce The Heist product on German TV. This advertisement classifies by the three meta-function:

\subsection{Ideational meta-function:}

a. In the image (1): I'm sorry, I'm just going to get into my Spyder.

The ideational meta-function represents the material process. I'm sorry is the actor, just going in the process, and into my Spyder is the goal.

b. In the image (2): Oooh, it's a beautiful day for a car chase.

The phrase involves the existential processes, in which it's in the process of existential, a beautiful day is existent, and for a car, the chase is the circumstance.

c. In the image (3): Who wants to be the bad guy next?

The phrase contains the material process. Who is the actor, wants to be in the process, and the bad guy next is the goal.

\subsubsection{Interpersonal meta-function}

The use of personal pronouns in these three images shares the interpersonal meta-function, the analysis will be explained in the following table:

\begin{tabular}{|l|l|l|}
\hline \multirow{2}{*}{$\begin{array}{l}\text { Image } \\
\text { No. }\end{array}$} & \multicolumn{2}{|l|}{ Theme } \\
\cline { 2 - 3 } & Interpersonal & \multicolumn{2}{|l|}{ Textual } \\
\hline 1 & going & just \\
\hline 2 & is & \\
\hline 3 & & next \\
& who & \\
\hline
\end{tabular}

\section{Table (9): Interpersonal Analysis of Automobile (The Heist) in American Advertisement}

The table below of the interpersonal and textual themes seen in these three images, and put each word in the theme type.

\subsubsection{Textual meta-function}

The analysis of these three images according to the major types of textual meta-function is mood and residue, as in:

\begin{tabular}{|c|c|c|c|c|c|c|}
\hline \multirow{2}{*}{$\begin{array}{l}\text { Image } \\
\text { No. }\end{array}$} & \multicolumn{2}{|l|}{ Mood } & \multicolumn{3}{|l|}{ Residue } & \multirow{2}{*}{ Types of Mood } \\
\hline & Subject & Finite & Predicator & Complement & Adjunct & \\
\hline 1 & $\begin{array}{l}1 \\
1\end{array}$ & $\begin{array}{l}\text { present } \\
\text { present }\end{array}$ & $\begin{array}{l}\text { am } \\
\text { am }\end{array}$ & $\begin{array}{l}\text { just } \\
\text { going }\end{array}$ & $\begin{array}{l}\text { to get into my } \\
\text { spyder }\end{array}$ & Declarative \\
\hline 2 & It & present & is & a beautiful day & for a car chase & Declarative \\
\hline 3 & The bad guy & present & & wants & next & rative \\
\hline
\end{tabular}

Table (10): Textual Analysis of Automobile (The Heist) in American Advertisement

All these three images involve the declarative mood. The advertiser uses these sentences in a declaratiye mood, to inform the viewers on TVs about the product of the car.

This advertisement is a car product. It generally promotes a type of heist. The image (4) of the advertisement car indicates the iconic sign. Image (4) is the signified, the thief who used in this advertisement to look a bad guy and to make a challenge between another car to show the power and the speed of the car. According to the two types of meaning, denotative and connotative 
meaning, Denotative meaning appears in of sequences in these three images in the image (1), there's a man who explains where he wants to go and by what, in the image (2), the man looks happy by his words, and the image (3) there's a man who looks like a thief of car and he offers to his friends about who wants to be a bad guy (thief) in the next game. Connotative meaning appears in the image (2) there's a man who steals the car and he drives it away. And this thief appears in the image (3). The scene means that these cars have the power to drive quickly in any situation. The place semiotics, for Scollen and Scollen, the place in the image (2) appears inside the car to indicate of power of it, and the place in the image (3) appears in the street to show the speed of cars. The gender that appears in this advertisement product is men because these guys work in the car selling company. So, in this case, it's important to use men rather than women.

\section{Conclusion}

American TV advertisements involve verbal aspects (text). These advertisements were introduced on American TV. Each advertisement includes text and gender. Accordingly, the modes employed to display the role of gender in American TV advertisements. So, the role of gender in advertisements is to persuade and encourage people about the product. American advertisements are biased to females rather than males to introduce the products because they considered females as powerful signs who use their high attractiveness to promote the products or brands. Concerning the grammatical aspects, it's shown that material process, mental process, declarative mood, and first-person pronouns are the highest used to achieve the goals of this study.

Funding: This research received no external funding

Conflicts of Interest: The authors declare no conflict of interest.

\section{References}

[1] Behnam, B. \& Zamanian, J. (2014). Gender and the Discourse of Advertising in English and Persian Magazine Advertisements. Vol. 4, No. 11. International Journal of Academic Research in Business and Social Sciences. https://www.researchgate.net/publication/287696772.

[2] Buren, V. (1992). The Semiotics of Gender. Journal of The American Academy of Psychoanalytic.

[3] Banks, D. (2002). Systemic Functional Linguistics as a Model for Text Analysis. Journals open edition. https://doi.org/10.4000/asp.1584.

[4] Eggins, S. (2004). An Introduction to Systemic Functional Linguistics (2nd ed.), Continuum International. Publishing Group.

[5] Richard, I. \& Curran, M. (2013). Oracles on "Advertising": Searching for a Definition. Article in Journal of Advertising. https://www.researchgate.net/publication/261655945.

[6] Halliday, M. A.K. (1994). System and Function in Language. (Ed. G. Kress). London: Oxford University Press. 